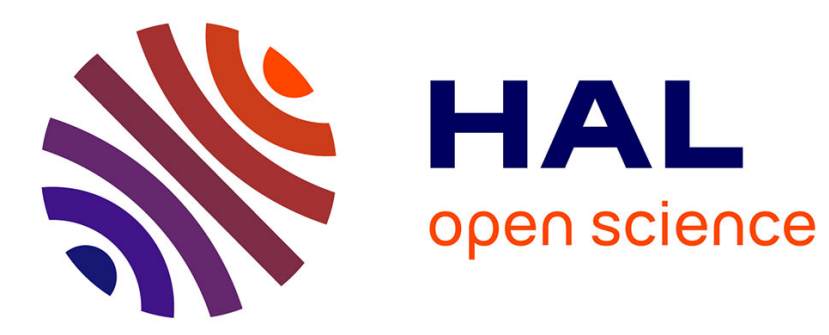

\title{
Utilisation quantitative du courant induit en microscopie électronique à balayage pour l'étude des composants silicium
}

\author{
J.F. Bresse
}

\section{- To cite this version:}

J.F. Bresse. Utilisation quantitative du courant induit en microscopie électronique à balayage pour l'étude des composants silicium. Revue de Physique Appliquée, 1974, 9 (2), pp.354-354. 10.1051/rphysap:0197400902035400 . jpa-00243786

\section{HAL Id: jpa-00243786 https://hal.science/jpa-00243786}

Submitted on 1 Jan 1974

HAL is a multi-disciplinary open access archive for the deposit and dissemination of scientific research documents, whether they are published or not. The documents may come from teaching and research institutions in France or abroad, or from public or private research centers.
L'archive ouverte pluridisciplinaire HAL, est destinée au dépôt et à la diffusion de documents scientifiques de niveau recherche, publiés ou non, émanant des établissements d'enseignement et de recherche français ou étrangers, des laboratoires publics ou privés. 


\title{
UTILISATION QUANTITATIVE DU COURANT INDUIT EN MICROSCOPIE ÉLECTRONIQUE A BALAYAGE POUR L'ÉTUDE DES COMPOSANTS SILICIUM
}

\author{
J. F. BRESSE
}

\author{
LETI/ME, C. E. N. G., BP 85, Centre de Tri, 38041 Grenoble, France \\ (article non parvenu)
}

Résumé. - Nous montrons comment le courant induit peut être utilisé sur des dispositifs Silicium planar pour la détermination de certains paramètres physiques : longueur de diffusion des minoritaires $(L)$, vitesse de recombinaison de surface $(S)$, produit mobilité durée de vie des électrons dans l'oxyde $\left(\mathrm{SiO}_{2}\right)$.

Abstract. - We show, in this paper, how the Electron Beam Induced Current (E. B. I. C.) can be used quantitatively on Silicon planar devices for the determination of some physical parameters : diffusion length of minority carriers $L$, surface recombination velocity $S$, mobility lifetime product of electrons in Silicon dioxide $(\mu \tau)$. 